\title{
Hepatic Arterial Infusion Chemotherapy for Liver Metastases Following Standard Chemotherapy for Pancreatic Cancer
}

\author{
Shinya Endo, Shinya Kawaguchi, Shuzo Terada and Naofumi Shirane
}

\begin{abstract}
:
A 65-year-old man diagnosed with locally advanced pancreatic cancer underwent distal pancreatectomy and combined portal vein resection. One month after surgery, contrast-enhanced magnetic resonance imaging revealed multiple liver metastases. We administered two courses of gemcitabine plus nab-paclitaxel combination therapy followed by 17 modified FOLFIRINOX courses. However, the response was insufficient, and the patient thereafter developed grade 3 neutropenia, which made it difficult to continue the treatment regimen. As a result, we administered hepatic arterial infusion chemotherapy comprising gemcitabine plus 5fluorouracil because the residual tumor was limited to liver metastases. The progression-free survival period was 7 months, and no drug-related adverse effects were noted during the treatment.
\end{abstract}

Key words: hepatic arterial infusion chemotherapy, liver metastases, recurrent pancreatic cancer

(Intern Med 60: 223-229, 2021)

(DOI: 10.2169/internalmedicine.5449-20)

\section{Introduction}

Pancreatic cancer is either the fourth or fifth most frequent cause of death from cancer in most developed countries. Despite developments in the detection and management of pancreatic cancer, only approximately $4 \%$ of patients are able to survive for 5 years after their diagnosis (1). In Japan, the median survival time (MST) of all patients with pancreatic cancer from 2001 to 2004 was 10.2 months, and the 3 -year survival rate was $11.7 \%$. The MST for all resected cases was 18.2 months, and the 3 -year survival rate was $23.2 \%$ (2).

Recurrent pancreatic cancer (RPC) generally has a poor prognosis. Groot et al. (3) reported that the median overall survival of 662 patients with postoperative recurrence of pancreatic cancer was 21.1 months. Chemotherapy is the standard therapy for RPC but it has limited efficacy and it is also associated with serious adverse events.

Hepatic arterial infusion chemotherapy (HAIC) is a treatment strategy that involves local delivery of anticancer drugs into the nutrient vessel of a tumor directly via an implant- able port to increase the concentration of drugs locally and reduce systemic adverse events. We herein report one patient who received HAIC for RPC that was limited to liver metastases following standard chemotherapy.

\section{Case Report}

A 65-year-old Japanese man was initially diagnosed with borderline resectable pancreatic cancer (solid tumor contacted with portal vein more than $180^{\circ}$, but allowing for safe and complete resection and vein reconstruction) (Fig. 1a, b). As no distant metastases and tumor progression were noted after neoadjuvant chemoradiation [30 Gy/10 fractions+oral tegafur/gimeracil/oteracil combination therapy (S-1) for 10 days], he underwent distal pancreatectomy and combined portal vein resection in September 2017. The tumor stage was found to be T3N1M0 (stage II b) according to the UICC TNM classification 8th edition (Fig. 1c, d). At 1 month after the surgery, contrast-enhanced magnetic resonance imaging revealed multiple liver metastases (Fig. 2).

Initially, we administered two courses of gemcitabine plus nab-paclitaxel (GnP); however, contrast-enhanced computed 

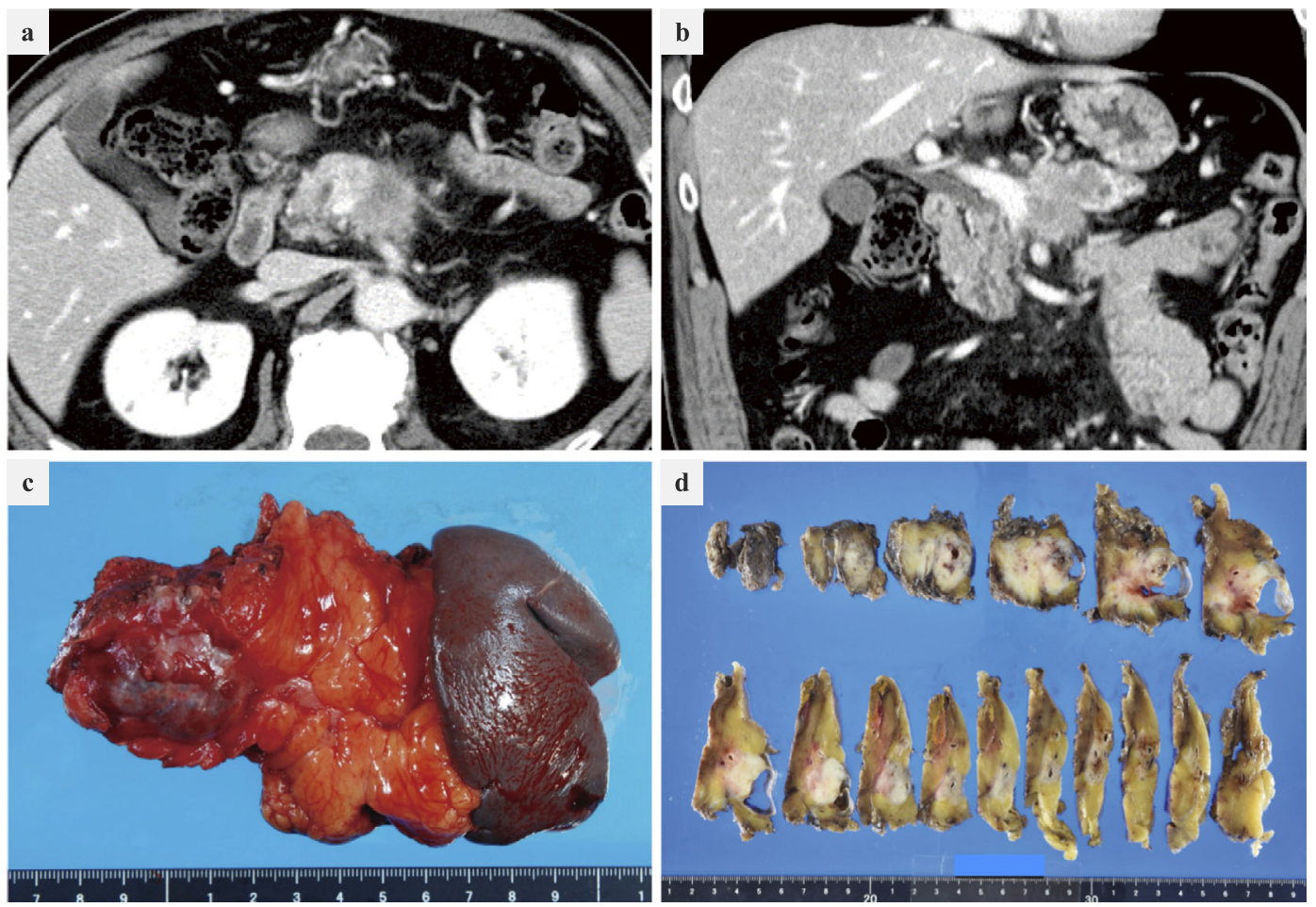

Figure 1. (a, b) Abdominal contrast-enhanced computed tomography image showing a 45-mm ischemic mass in the pancreatic body. (c, d) Resected pancreatic cancer specimen. Pathological examination reveals invasive ductal carcinoma of the pancreas body with two metastatic regional lymph nodes. The tumor stage was found to be T3N1M0 (stage II b) according to the UICC TNM classification 8th edition.

tomography after 2 months showed tumor growth, and we could not continue the treatment according to the standard regimen because the patient developed grade 3 neutropenia. Thereafter, we administered 17 courses of modified FOLFIRINOX. However, as grade 3 neutropenia in the patient recurred, we had to administer granulocyte colonystimulating factor (G-CSF) concomitantly to continue the treatment according to the standard regimen. In addition, renal dysfunction, neuralgia, and dysgeusia (all grade 1) were all observed (Fig. 3). The treatment seemed to be effective, but nevertheless both the tumor and tumor markers increased again.

As the residual tumor was limited to liver metastases, we administered HAIC using gemcitabine (GEM) and 5fluorouracil (5-FU) after obtaining approval from the relevant ethical review board in October 2018. We placed an anticoagulant-coated indwelling catheter (5-Fr W spiral catheter, Piolax Medical Devices, Yokohama, Japan) into the peripheral branch of the hepatic artery and positioned the handmade side hole at the common hepatic artery (Fig. 4). Then, we connected the catheter to a subcutaneous implantable port system located in the right thigh. GEM [800 mg/ standard liver volume (SLV)] was administered over $30 \mathrm{~min}$ on the 1st day. Subsequently, $250 \mathrm{mg}$ of 5-FU was administered continuously over 24 hours for days 1-6. Each treatment cycle was continued biweekly (Fig. 5). The SLV was calculated as follows: (706.2×body surface area+2.4)/ 1,000 (4).
We administered a total of 14 courses of the regimen. The progression-free-survival period was 7 months (Fig. 6), and no drug-related adverse events were noted during treatment (Fig. 7). The overall status of the patient was generally good. However, after the 14 th cycle ( 7 months since the initial HAIC), peritoneal dissemination was detected. Thereafter, additional systemic chemotherapy comprising GEM plus S-1 was performed, but could not be continued owing to a jejunal passage disorder. The patient was able to eat after gastrojejunostomy, but his general condition did not improve sufficiently to continue additional chemotherapy. He died 2 years after the initial visit.

\section{Discussion}

After the radical resection of pancreatic cancer, approximately $80 \%$ of patients would develop recurrence (3). A meta-analysis showed that the weighted median rate of initial recurrence in the liver after resection of pancreatic cancer was $26.5 \%$ (5). Pancreatic cancer has a poor prognosis for postoperative recurrence, especially liver recurrence $(3,6)$. Therefore, the control of liver recurrence is important to improve the prognosis after surgery.

Chemotherapy is the standard therapy for RPC but has limited efficacy. In Japan, FOLFIRINOX and GnP are used as first-line therapies. However, the MST in phase-III studies has not been satisfactory (11.1 and 8.5 months for FOLFIRINOX and GnP, respectively) (7, 8). Furthermore, chemo- 

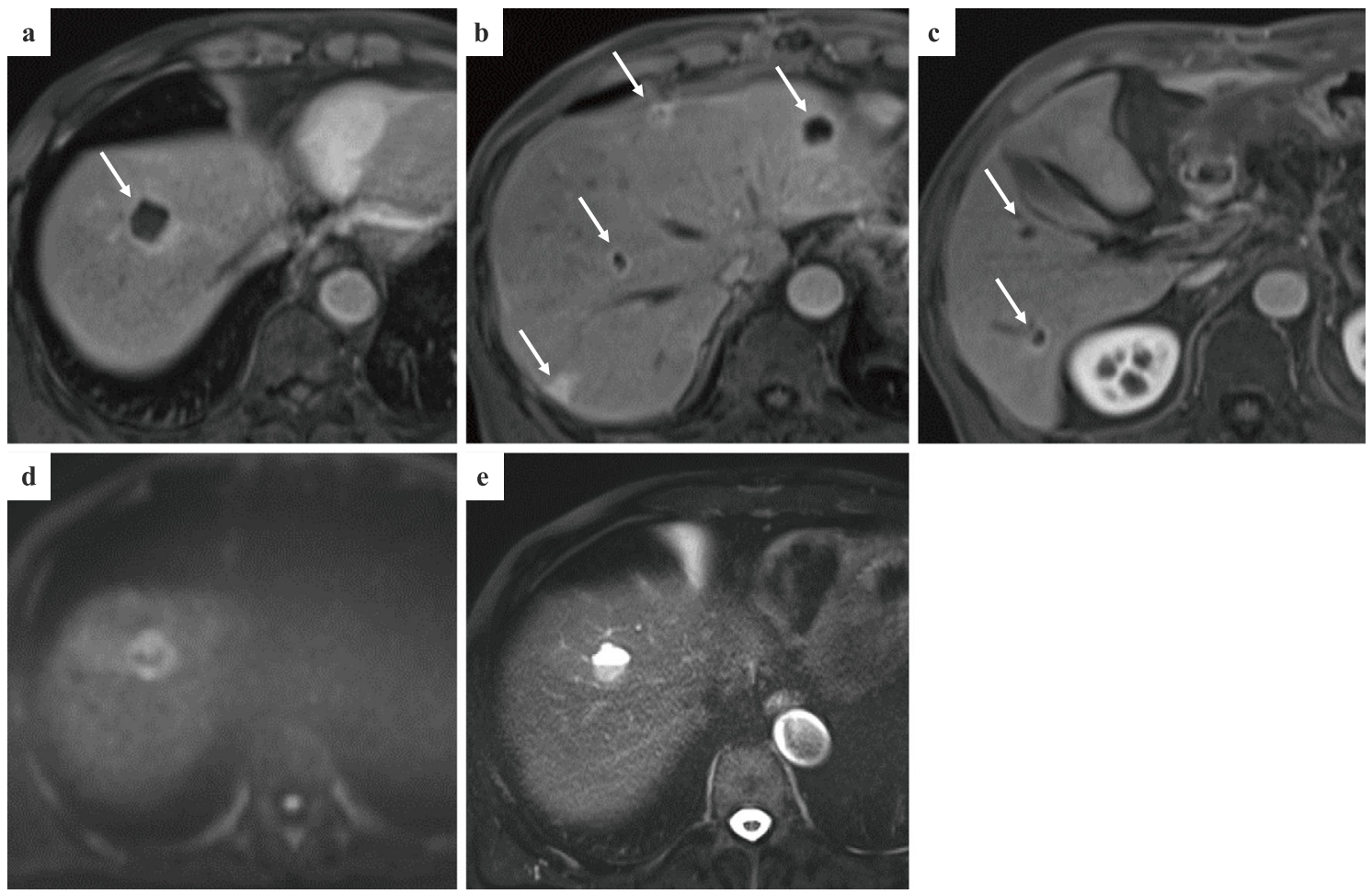

Figure 2. (a-c) One month after the surgery, gadolinium ethoxybenzyl-diethylenetriamine pentaacetic acid-enhanced magnetic resonance imaging revealed new multiple tumors with perilesional ring enhancement in the arterial phase (arrows). (d) Diffusion-weighted image shows perilesional high signal that is not shown in the center. (e) T2-weighted HASTE image shows hyperintense lesions with a fluid-fluid level, which is considered to be an intratumoral hemorrhage. There were no symptoms or blood biochemical findings suggestive of infection; therefore, we ruled out abscesses from our differential, and considered the presence of multiple lesions to be metastases. HASTE: half-Fourier acquisition single-shot turbo spin echo

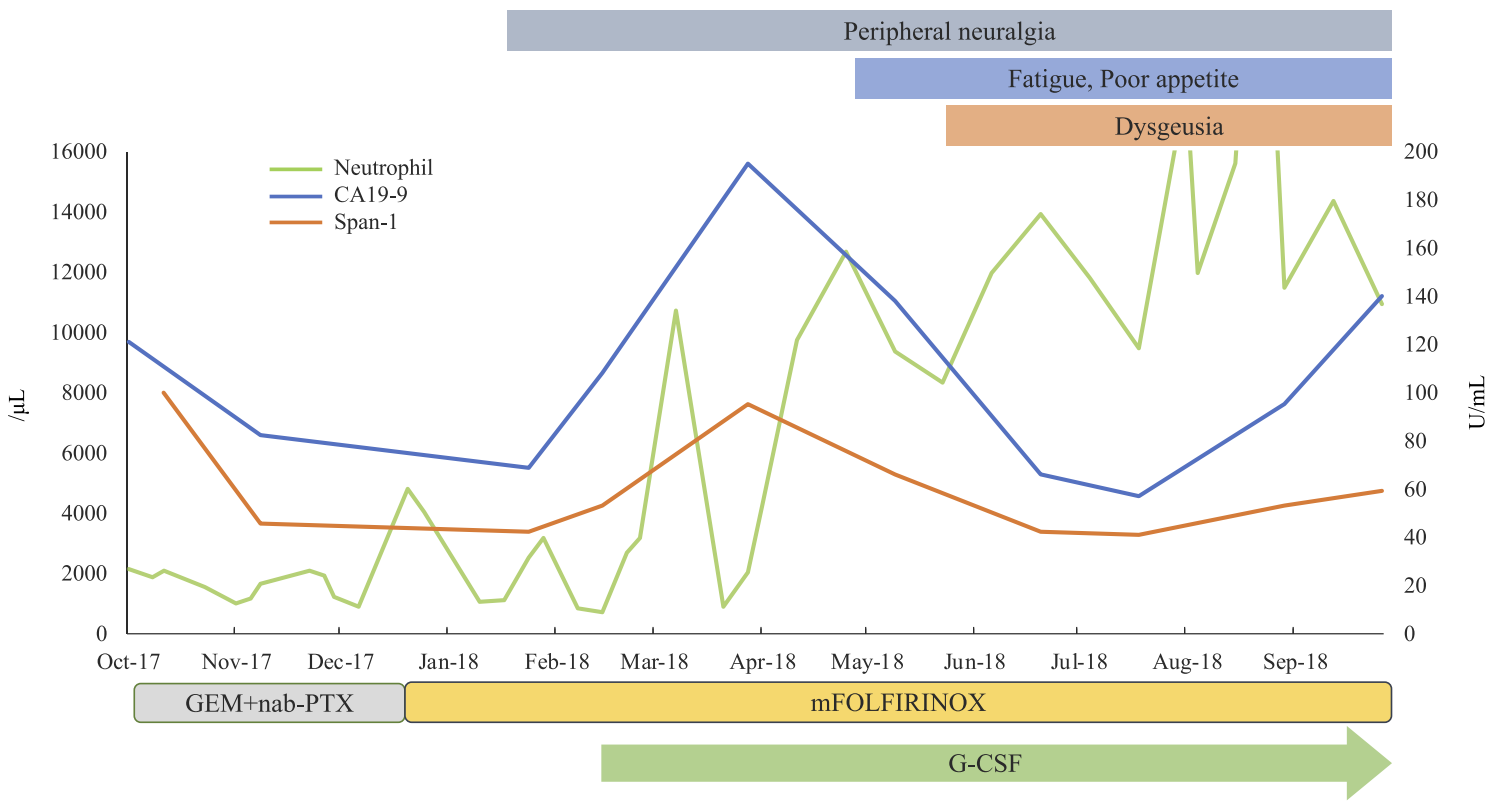

Figure 3. The clinical course of the patient after surgery, along with the details of the course of chemotherapy and adverse events. G-CSF had to be administered to the patient for grade 3 neutropenia. G-CSF: granulocyte colony-stimulating factor 

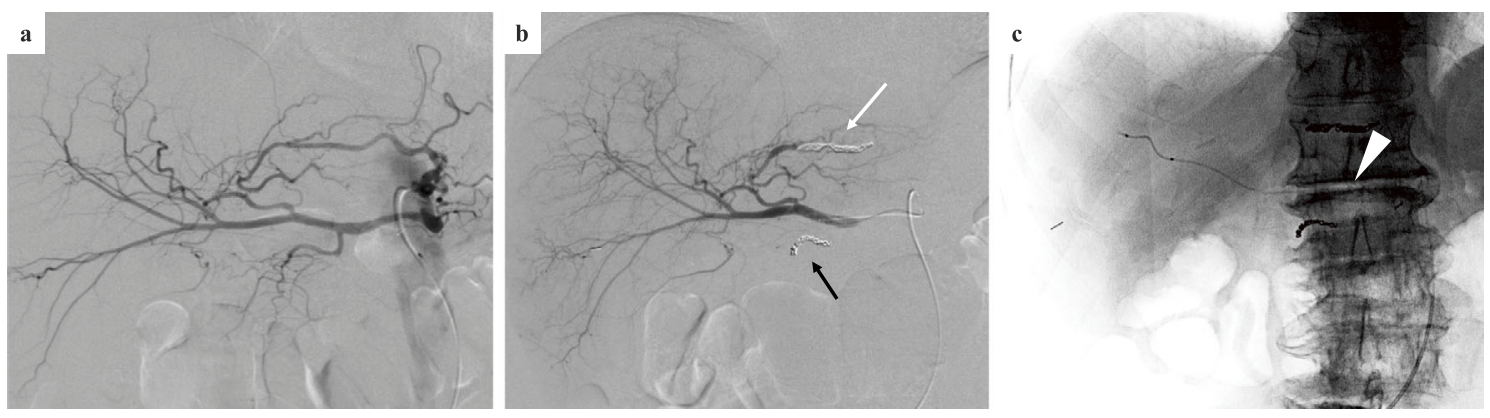

Figure 4. (a) Abdominal angiogram revealing the replaced left hepatic artery. (b) It was embolized with microcoils to redistribute the entire hepatic arterial flow from multiple arteries into a single artery (white arrow). The gastroduodenal artery was also embolized to prevent chemotherapeutic agent distribution to the gastrointestinal tract (black arrow). (c) An anticoagulant-coated indwelling catheter (5-Fr W spiral catheter, Piolax Medical Devices, Yokohama, Japan) was placed. The catheter tip was inserted into the peripheral branch of the hepatic artery, and the handmade side hole (arrow head) was positioned at the common hepatic artery.

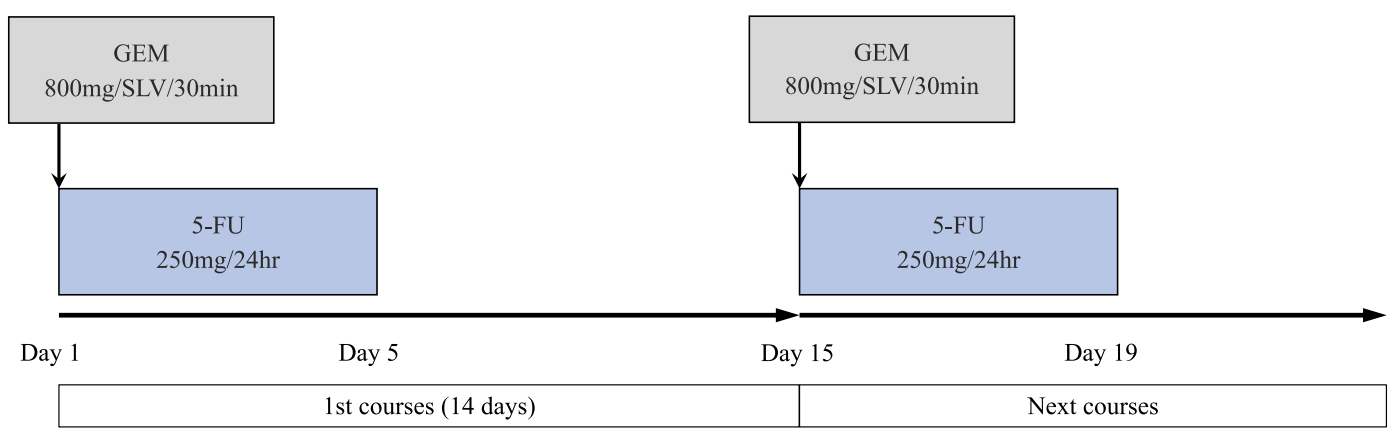

Figure 5. The treatment regimen of hepatic arterial infusion chemotherapy (GEM plus 5-FU combination therapy). GEM (800 mg/SLV) was administered over $30 \mathrm{~min}$ on the 1st day. Subsequently, $250 \mathrm{mg}$ of 5-FU was continuously administered over 24-h for days 1-6. Each treatment cycle was continued biweekly. The SLV was calculated as follows: $(706.2 \times$ body surface area+2.4)/1,000 (4). GEM: gemcitabine, 5-FU: 5-fluorouracil, SLV: standard liver volume

therapy is associated with serious adverse events. In phaseIII studies, grade 3 or 4 neutropenia occurred in $45.7 \%$ and $37.8 \%$ of cases for FOLFIRINOX and GnP, respectively $(7,8)$. In the present case, the patient could not continue treatment with the standard drug volumes and needed concomitant G-CSF for severe neutropenia due to systemic chemotherapy. At present there is no strongly recommended second-line therapy (9). As such, we often experience a lack of chemotherapeutic methods and selectable drugs despite a patient's good general condition.

Arterial infusion is suggested to take advantage of the first pass effect of chemotherapeutic drugs by increasing their concentrations locally at the tumor cell membrane and enhancing cellular drug uptake (10). Previous reports, in which HAIC was used as an adjuvant chemotherapy or treatment for postoperative liver metastases for pancreatic cancer, are summarized in Table (11-18). There are many regimens using 5-FU and GEM. Adjuvant chemotherapy is common, and there are few reports where HAIC was used as a treatment for postoperative liver metastases. Hashimoto et al. (11) performed HAIC using 5-FU combined with sys- temic GEM for liver metastases after pancreatectomy in nine patients. In their report, the overall response and disease control rates were $44.4 \%$ and $88.9 \%$, respectively. There were two cases of a complete response. The appropriate hepatic arterial infusion doses and flow rates for GEM and 5FU have been reported previously (19-23). Tajima et al. (23) analyzed seven cases, in which the GEM concentration in the peripheral blood was measured after hepatic arterial infusion and concluded that $800 \mathrm{mg} / \mathrm{SLV}$ was the optimal dose. Tajima et al. (12) also adopted $250 \mathrm{mg}$ of 5-FU as a dose with low adverse events based on peripheral blood concentrations when injected into the hepatic artery over a 24-h period. Their regimen was referred to in the present case.

HAIC seemed to be effective in the present case. A unique aspect of this case was the fact that the effect could be obtained by changing the drug administration method used in the preceding systemic chemotherapy to arterial injection. It was also noteworthy that the patient lived a normal life without any adverse events during the treatment course. 

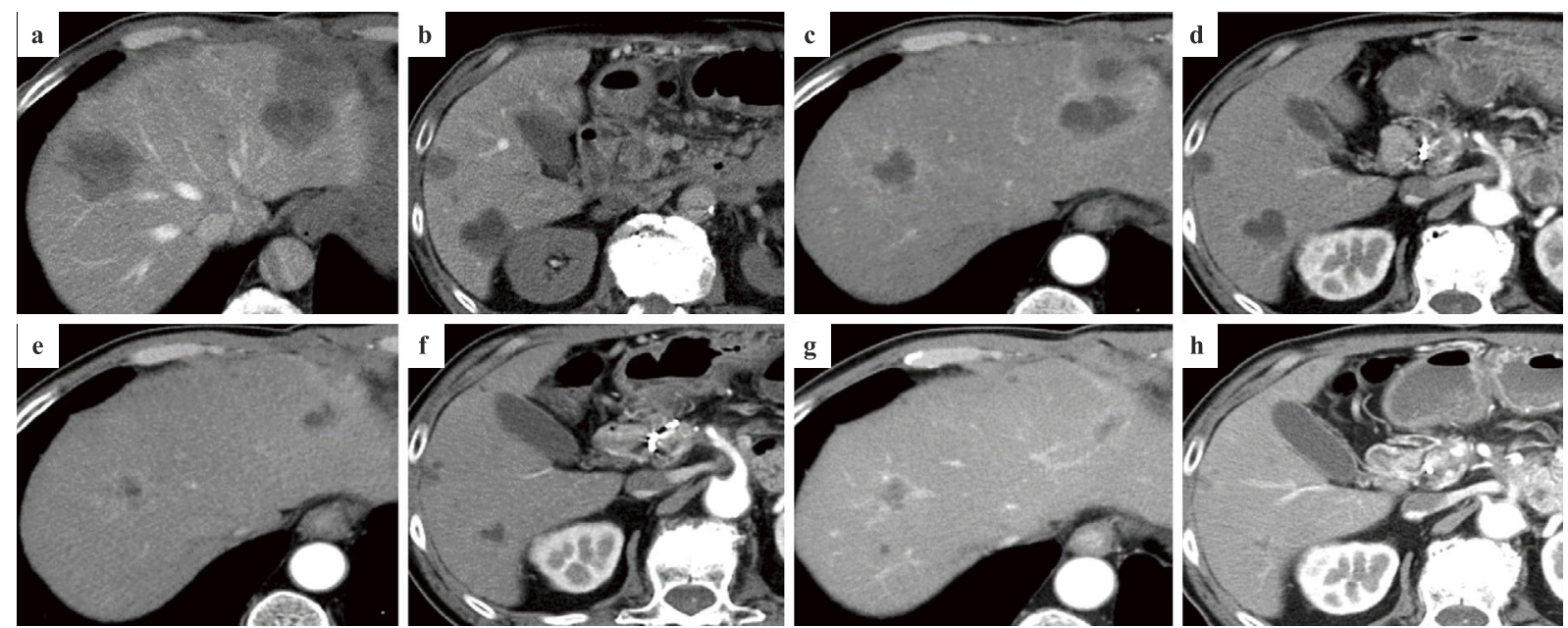

Figure 6. Follow-up contrast-enhanced computed tomographic image revealing a decrease in the size of the liver metastases. There was no local recurrence or distant metastasis except for the liver. (a, b) Computed tomography findings during arterial portography before HAIC; (c, d) after the second treatment cycle; $(\mathrm{e}, \mathrm{f})$ after the sixth treatment cycle; $(\mathrm{g}, \mathrm{h})$ after the 10th treatment cycle. HAIC: hepatic arterial infusion chemotherapy

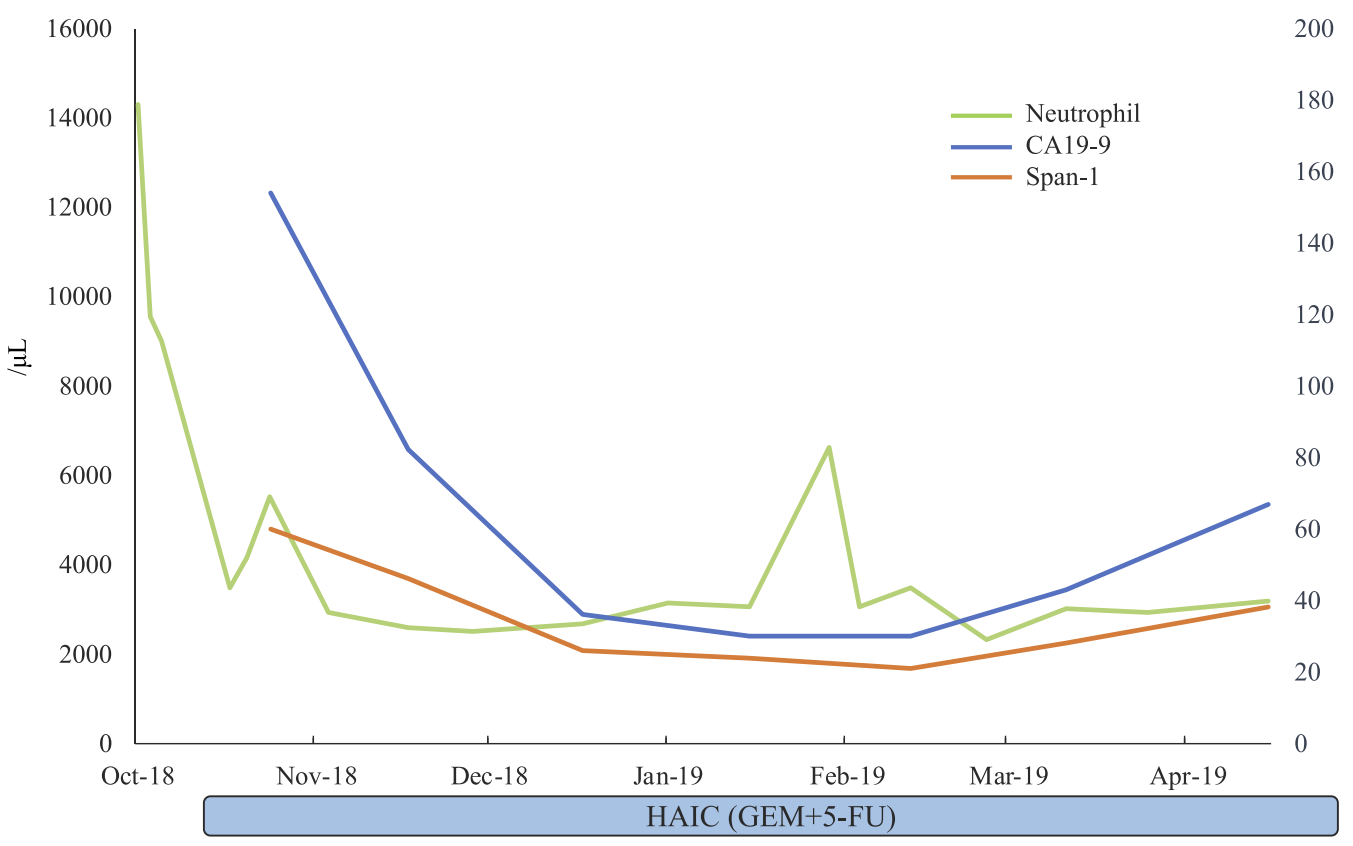

Figure 7. The clinical course of the patient. Hepatic arterial infusion chemotherapy was continued up to the 14th cycle without any adverse events. The graph shows the reduction of tumor markers and stable neutrophil count.

One of the disadvantages in the use of the regimen adopted in the present case was that it required the hospitalization of patients for 5-6 days every 2 weeks. It is important to devise a dosing regimen that allows outpatient chemotherapy to improve patient acceptance. It may also be possible to improve the therapeutic effect by changing the order of administration of chemotherapeutic drugs (e.g., administering 5-FU before GEM). 5-FU leads to an increase in the major mediator of the cellular uptake of GEM (24). In addition, it is unclear whether controlling liver metastases with HAIC improves the prognoses. In our case, peritoneal dis- semination was finally deemed to be associated with the prognosis. Pancreatic cancer is a systemic disease and the application of local therapy alone presents critical limitations. Zheng et al. (13) in their randomized controlled trial reported that HAIC combined with systemic chemotherapy after pancreatectomy for pancreatic cancer significantly prevented liver metastases and improved the prognosis compared with systemic chemotherapy only. Their report does not adapt to chemotherapy for recurrent tumors, which was similar to that in our case, but it is important evidence that the combination of HAIC and systemic chemotherapy im- 
Table. Previous Reports of Hepatic Arterial Infusion Chemotherapy as an Adjuvant Chemotherapy or Treatment for Postoperative Liver Metastases for Pancreatic Cancer (excluding Case Reports).

\begin{tabular}{|c|c|c|c|c|c|c|c|c|}
\hline Reference & $\begin{array}{l}\text { Study } \\
\text { design }\end{array}$ & $\mathbf{n}$ & Aim & $\begin{array}{c}\text { Treatment } \\
\text { before HAIC }\end{array}$ & HAIC Regimen & $\begin{array}{c}\text { Concurrent } \\
\text { therapy or } \\
\text { Monotherapy }\end{array}$ & $\begin{array}{l}\text { Followed } \\
\text { treatment }\end{array}$ & MST \\
\hline 14 & prospective & 15 & ACT & $\begin{array}{c}\text { NACRT } \\
24 \mathrm{~Gy}+5-\mathrm{FU}\end{array}$ & $\begin{array}{c}5-\mathrm{FU} 125 \mathrm{mg} / \mathrm{d} \\
28 \text { days }\end{array}$ & $\begin{array}{c}\text { +LPC via portal } \\
\text { vein 5-FU 125mg/ } \\
\text { d 28days }\end{array}$ & $\begin{array}{c}\text { CRT 36Gy+SCT } \\
\text { 5-FU 500mg/d } \\
\text { 6days }\end{array}$ & $62.0 \mathrm{~m}$ \\
\hline 15 & $\begin{array}{l}\text { prospective } \\
\text { phase2 study }\end{array}$ & 27 & ACT & & $\begin{array}{c}5 \text {-FU } 125 \mathrm{mg} / 24 \mathrm{~h} \\
21-28 \text { days }\end{array}$ & $\begin{array}{l}\text { +LPC via portal } \\
\text { vein } 5-\mathrm{FU} \\
125 \mathrm{mg} / 24 \mathrm{~h} \\
21-28 \text { days }\end{array}$ & $\begin{array}{c}\text { SCT GEM } \\
1,000 \mathrm{mg} / \mathrm{m} 2 / 2 \mathrm{w}, \\
\text { at least } 12 \mathrm{c}\end{array}$ & $27.5 \mathrm{~m}$ \\
\hline 16 & pilot study & 5 & $\begin{array}{l}\text { chemotherapy } \\
\text { for PLM }\end{array}$ & $\begin{array}{c} \pm \mathrm{NAC} \\
\text { GEM+S-1, } \\
\pm \mathrm{ACT} \text { GEM }\end{array}$ & $\begin{array}{c}\text { GEM 800mg } \\
\begin{array}{c}\text { (d1)+5-FU 250mg } \\
(\mathrm{d} 1-5) / 2 \mathrm{w}\end{array}\end{array}$ & & & $22.4 \mathrm{~m}$ \\
\hline 17 & retrospective & 31 & ACT & & $\begin{array}{c}5-\mathrm{FU} 1,000 \mathrm{mg} / \\
\mathrm{m} 2(\mathrm{~d} 1,8,15) / \\
4 \mathrm{w}, 3 \mathrm{c}\end{array}$ & $\begin{array}{c} \pm \text { SCT GEM } \\
1,000 \mathrm{mg} / \mathrm{m} 2(\mathrm{~d} 1, \\
8,15) / 4 \mathrm{w}, 3 \mathrm{c}\end{array}$ & $\begin{array}{c}\text { SCT GEM } \\
1,000 \mathrm{mg} / \mathrm{m} 2(\mathrm{~d} 1,8 \\
15) / 4 \mathrm{w}, 3 \mathrm{c}\end{array}$ & $37.7 \mathrm{~m}$ \\
\hline \multirow[t]{2}{*}{11} & retrospective & $9 *$ & $\begin{array}{l}\text { chemotherapy } \\
\text { for PLM }\end{array}$ & $\begin{array}{c} \pm \text { NACRT } \\
50-54 \mathrm{~Gy}+\mathrm{GEM}\end{array}$ & $\begin{array}{l}5-\mathrm{FU} 1,000 \mathrm{mg} / \\
\mathrm{m} 2(\mathrm{~d} 1,8,15) / 4 \mathrm{w}, \\
\text { repeated }\end{array}$ & $\begin{array}{l} \pm \text { SCT GEM } \\
1,000 \mathrm{mg} / \mathrm{m} 2\end{array}$ & & $14.1 \mathrm{~m} \dagger$ \\
\hline & & $42 *$ & ACT & & $\begin{array}{c}5-\mathrm{FU} 1,000 \mathrm{mg} / \\
\mathrm{m} 2(\mathrm{~d} 1,8,15) / 4 \mathrm{w}, \\
3 \mathrm{c}\end{array}$ & $\begin{array}{l} \pm \text { SCT GEM } \\
1,000 \mathrm{mg} / \mathrm{m} 2\end{array}$ & & $36.8 \mathrm{~m}$ \\
\hline \multirow[t]{2}{*}{12} & retrospective & 5 & $\begin{array}{l}\text { chemotherapy } \\
\text { for PLM }\end{array}$ & $\begin{array}{c} \pm \mathrm{NAC} \\
\text { GEM+S-1, } \\
\pm \text { ACT GEM }\end{array}$ & $\begin{array}{c}\text { GEM 800mg/ } \\
\text { SLV(d1)+5-FU } \\
250 \mathrm{mg} / \mathrm{SLV} / 24 \mathrm{~h} \\
(\mathrm{~d} 1-5) / 2 \mathrm{w}\end{array}$ & & & $22.4 \mathrm{~m}$ \\
\hline & & 2 & & & $\begin{array}{l}\text { GEM 800mg/ } \\
\text { SLV(d8)/2w }\end{array}$ & $\begin{array}{c}+\mathrm{S}-160 \mathrm{mg} / \mathrm{m} 2 / \mathrm{d} \\
(\mathrm{d} 1-7) / 2 \mathrm{w}\end{array}$ & & \\
\hline \multirow[t]{2}{*}{13} & $\mathrm{RCT}$ & 52 & ACT & & $\begin{array}{c}\text { GEM } 800 \mathrm{mg} / \mathrm{m} 2 \\
(\mathrm{~d} 1,8)+5-\mathrm{FU} \\
1,000 \mathrm{mg} / \mathrm{m} 2(\mathrm{~d} 1), \\
2 \mathrm{c}\end{array}$ & & $\begin{array}{c}\text { SCT GEM 800mg/ } \\
\mathrm{m} 2(\mathrm{~d} 1,8)+5-\mathrm{FU} \\
1,000 \mathrm{mg} / \mathrm{m} 2(\mathrm{~d} 1) \\
4 \mathrm{c}\end{array}$ & $30.0 \mathrm{~m} \neq$ \\
\hline & & 54 & & & & $\begin{array}{c}\text { SCT GEM } 800 \mathrm{mg} / \\
\mathrm{m} 2(\mathrm{~d} 1,8)+5-\mathrm{FU} \\
1,000 \mathrm{mg} / \mathrm{m} 2(\mathrm{~d} 1) \\
6 \mathrm{c}\end{array}$ & & $23.0 \mathrm{~m} \neq$ \\
\hline 18 & retrospective & 93 & $\mathrm{ACT}$ & $\begin{array}{c} \pm \text { NACRT } \\
50-54 \mathrm{~Gy}+\mathrm{GEM}\end{array}$ & $\begin{array}{c}5-\mathrm{FU} 1,000 \mathrm{mg} / \\
\mathrm{m} 2(\mathrm{~d} 1,8 \\
15) / 4 \mathrm{w}, 3 \mathrm{c}\end{array}$ & $\begin{array}{c}\text { +SCT GEM } \\
1,000 \mathrm{mg} / \mathrm{m} 2(\mathrm{~d} 1 \\
8,15) / 4 \mathrm{w}\end{array}$ & SCT GEM, 3c & $44.0 \mathrm{~m}$ \\
\hline
\end{tabular}

\footnotetext{
*: includes 2 periampullary cancer, $\uparrow:$ median survival time from beginning of HAIC, $\$$ : inferred from Kaplan-Meier curve. ACT: adjuvant chemotherapy, PLM: postoperative liver metastases, HAIC: hepatic arterial infusion chemotherapy, NACRT: neoadjuvant chemoradiotherapy, NAC: neoadjuvant chemotherapy, LPC: liver perfusion chemotherapy, SCT: systemic chemotherapy, CRT: chemoradiotherapy, RCT: randomized controlled trial, 5-FU: 5-fluorouracil, GEM: gemcitabine, S-1: oral tegafur/gimeracil/oteracil combination therapy, SLV: standard liver volume, n: number of patients, MST: median survival time, c: cycles, h: hours, d: day, w: weeks, m: months
}

proved the prognosis of patients after surgery for pancreatic cancer. To perform effective treatments, it is therefore important to consider a combination of HAIC with systemic chemotherapy to control local recurrences and occult extrahepatic metastases.

To date, HAIC appears to be a useful method for local control in cases where effective chemotherapy cannot be administered in sufficient volume due to adverse events caused by systemic administration, and it plays a significant role in performing effective multidisciplinary treatment.

\section{Conclusion}

In the present case, HAIC caused no major adverse events and it may therefore be a useful technique for administering chemotherapy for the local control of RPC that is limited to liver metastases.

The authors state that they have no Conflict of Interest (COI).

\section{References}

1. Raimondi S, Maisonneuve P, Lowenfels AB. Epidemiology of pancreatic cancer: an overview. Nat Rev Gastroenterol Hepatol 6: 699-708, 2009.

2. Egawa S, Toma $\mathrm{H}$, Ohigashi $\mathrm{H}$, et al. A digest of the pancreatic cancer registry report 2007. Suizo 23: 105-123, 2008 (in Japanese, Abstract in English).

3. Groot VP, Gemenetzis G, Blair AB, et al. Implications of the pattern of disease recurrence on survival following pancreatectomy for pancreatic ductal adenocarcinoma. Ann Surg Oncol 25: 24752483, 2018. 
4. Urata K, Kawasaki S, Matsunami H, et al. Calculation of child and adult standard liver volume for liver transplantation. Hepatology 21: 1317-1321, 1995.

5. Tanaka M, Mihaljevic AL, Probst $P$, et al. Meta-analysis of recurrence pattern after resection for pancreatic cancer. Br J Surg 106: 1590-1601, 2019.

6. Suenaga M, Fujii T, Kanda M, et al. Pattern of first recurrent lesions in pancreatic cancer: hepatic relapse is associated with dismal prognosis and portal vein invasion. Hepatogastroenterology 61: 1756-1761, 2014.

7. Conroy T, Desseigne F, Ychou M, et al. FOLFIRINOX versus gemcitabine for metastatic pancreatic cancer. N Engl J Med 364: 1817-1825, 2011.

8. Von Hoff DD, Ervin T, Arena FP, et al. Increased survival in pancreatic cancer with nab-paclitaxel plus gemcitabine. N Engl J Med 369: 1691-1703, 2013

9. Okusaka T, Nakamura M, Yoshida M, et al. Clinical practice guidelines for pancreatic cancer 2019 from the Japan Pancreas Society: a synopsis. Pancreas 49: 326-335, 2020.

10. Aigner KR. Intra-arterial infusion: overview and novel approaches. Semin Surg Oncol 14: 248-253, 1998.

11. Hashimoto A, Nishiofuku H, Tanaka T, et al. Safety and optima management of hepatic arterial infusion chemotherapy after pancreatectomy for pancreatobiliary cancer. Am J Roentgenol 198: 923-930, 2012

12. Tajima H, Kitagawa $H$, Tsukada $T$, et al. Hepatic arterial infusion chemotherapy with gemcitabine and 5-fluorouracil or oral S-1 improves the prognosis of patients with postoperative liver metastases from pancreatic cancer. Mole Clin Oncol 1: 869-874, 2013.

13. Zheng YY, Tang CW, Xu YQ, Feng WM, Bao Y, Fei MY. Hepatic arterial infusion chemotherapy reduced hepatic metastases from pancreatic cancer after pancreatectomy. Hepatogastroenterology 61: 1415-1420, 2014.

14. Ohigashi $\mathrm{H}$, Ishikawa $\mathrm{O}$, Eguchi $\mathrm{H}$, et al. Feasibility and efficacy of combination therapy with preoperative and postoperative chemoradiation, extended pancreatectomy, and postoperative liver perfusion chemotherapy for locally advanced cancers of the pancreatic head. Ann Surg Oncol 12: 629-636, 2005.

15. Kurosaki I, Kawachi Y, Nihei K, et al. Liver perfusion chemotherapy with 5-Fluorouracil followed by systemic gemcitabine administration for resected pancreatic cancer: preliminary results of a prospective phase 2 study. Pancreas 38: 161-167, 2009.
16. Tajima H, Ohta $T$, Kitagawa $H$, et al. Pilot study of hepatic arterial infusion chemotherapy with gemcitabine and 5-fluorouracil for patients with postoperative liver metastases from pancreatic cancer. Exp Ther Med 2: 265-269, 2011.

17. Sho M, Tanaka $T$, Yamada $T$, et al. Novel postoperative adjuvant strategy prevents early hepatic recurrence after resection of pancreatic cancer. J Hepatobiliary Pancreat Sci 18: 235-240, 2011.

18. Hashimoto A, Tanaka T, Sho M, et al. Adjuvant hepatic arterial infusion chemotherapy after resection for pancreatic cancer using coaxial catheter-port system compared with conventional system. Cardiovasc Intervent Radiol 39: 831-839, 2016.

19. Miyanishi $K$, Ishiwatari $H$, Hayashi $T$, et al. A phase I trial of arterial infusion chemotherapy with gemcitabine and 5-fluorouracil for unresectable advanced pancreatic cancer after vascular supply distribution via superselective embolization. Jpn J Clin Oncol 38: 268-274, 2008.

20. van Riel JM, Peters GJ, Mammatas LH, et al. A phase I and pharmacokinetic study of gemcitabine given by $24-\mathrm{h}$ hepatic arterial infusion. Eur J Cancer 45: 2519-2527, 2009.

21. Vogl TJ, Schwarz W, Eichler K, et al. Hepatic intraarterial chemotherapy with gemcitabine in patients with unresectable cholangiocarcinomas and liver metastases of pancreatic cancer: a clinical study on maximum tolerable dose and treatment efficacy. J Cancer Res Clin Oncol 132: 745-755, 2006.

22. Maruyama S, Ando M, Watayo T. Concentration of 5-FU after hepatic artery infusion chemotherapy for liver metastases of colorectal cancer. Gan To Kagaku Ryoho (Jpn J Cancer Chemother) 30: 1635-1638, 2003 (in Japanese, Abstract in English).

23. Tajima $H$, Kitagawa $H$, Shoji $M$, et al. Hepatic arterial Infusion chemotherapy with gemcitabine for patients with postoperative liver metastases from pancreatic cancer. Gan To Kagaku Ryoho (Jpn J Cancer Chemother) 40: 1668-1671, 2013 (in Japanese, Abstract in English).

24. Nakahira S, Nakamori S, Tsujie M, et al. Pretreatment with S-1, an oral derivative of 5-fluorouracil, enhances gemcitabine effects in pancreatic cancer xenografts. Anticancer Res 28: 179-186, 2008 .

The Internal Medicine is an Open Access journal distributed under the Creative Commons Attribution-NonCommercial-NoDerivatives 4.0 International License. To view the details of this license, please visit (https://creativecommons.org/licenses/ by-nc-nd/4.0/).

(C) 2021 The Japanese Society of Internal Medicine Intern Med 60: 223-229, 2021 